\title{
EFFECT OF METHYLXANTHINES ON URINARY PROSTAGLANDIN E EXCRETION IN RATS*
}

\author{
Kumeji TAKEUCHI, Hiroshi KOGO and Yoshio AIZAWA \\ Department of Pharmacology, Tokyo College of Pharmacy, \\ 1432-1 Horinouchi, Hachioji, Tokyo 192-03, Japan
}

Accepted December 4, 1980

\begin{abstract}
Effect of methylxanthines (theophylline, theobromine and caffeine) on urinary prostaglandin $E$ (PGE) excretion in male rats was studied. Oral administration of xanthines significantly increased the urinary excretion of PGE. Dose-response studies showed that the maximal excretion of urinary PGE and water was obtained by administration of theophylline $(50 \mathrm{mg} / \mathrm{kg})$. Where the increase in PGE was about 20 times that of the control. The excretion of urinary sodium, potassium and chloride was also markedly increased by xanthines, particularly, theophylline. Increases in urinary PGE excretion, urine volume and electrolytes excretion were inhibited by $10 \mathrm{mg} / \mathrm{kg}$ of indomethacin administered prior to theophylline. The increase of urinary PGE excretion after theophylline administration $(50 \mathrm{mg} / \mathrm{kg}$ ) preceded increases in water and sodium excretion. These results suggest that renal PGE mediates, at least in part, the diuretic effect of theophylline.
\end{abstract}

Prostaglandins (PGS) having physiological activity are excreted in the urine of humans $(1,2)$, dogs $(3,4)$, rabbits $(5,6)$ and rats $(7)$. The kidney is considered to be the origin of urinary PGs and PGs in the urine reflect the synthesis of these compounds in the kidney and/or the release of PGs from kidney ( 3 . 4). Renal blood flow, urine volume and sodium excretion are reportedly increased by PGE, the main component of renal PGs, without changes in the glomerular filtration rate $(G f R)(8)$. With regard to the relationship between the renal vascular system and PGs, angiotensin (3) and bradykinin (9) contraction or dilate renal vessels and increase excretion of urinary PGE. Also, it has been

"This work was presented at the 53rd General Meeting of the Japanese Pharmacological Society in Gifu, Japan, March, 1980. shown that the excretion of urinary PGs is stimulated by furosemide (1, 5, 10, 11). ethacrynic acid (10) and spironolactone (12). These observations suggest that PGs play an important role in the mechanism of diuretic action. Methylxanthines also increase renal blood flow, sodium excretion and urine volume (13). We attempted to determine whether renal PGs mediate the diuretic action of xanthines.

\section{MATERIALS AND METHODS}

Male Wistar rats, weighing $270-300 \mathrm{~g}$ were fed standard pellet diet $(0.69 \% \mathrm{~K}$ : $0.24 \% \mathrm{Na}$ ) with free access to water. Food was withdrawn $3 \mathrm{hr}$ before the experiment, and the animals were allowed to drink water freely during the test period. Theophylline, theobromine and caffeine suspended in 
$0.9 \% \mathrm{NaCl}$ solution were given p.o. each in a volume of $0.5 \mathrm{ml} / \mathrm{rat}$. Indomethacin was suspended in $5 \%$ gummi arabicum solution and given p.o. in a dose of $10 \mathrm{mg} / \mathrm{kg}$ in a volume of $0.5 \mathrm{ml} / \mathrm{rat}, 1 \mathrm{hr}$ before administration of the methylxanthines. Each animal was housed individually in a metabolic cage immediately after the administration of the drugs and the total urine out put was collected. Each control animal was given the same volume of $0.9 \% \mathrm{NaCl}$ or $5 \%$ gummi arabicum solution.

The extraction and the assay of PGs from the urine sample were carried out by the method previously reported (7): The urine sample of $5 \mathrm{ml}$ diluted with water was acidified $(\mathrm{pH} 3)$ with $1 \mathrm{~N}-\mathrm{HCl}$ on an ice-cold water bath, and $P G s$ in urine were extracted with $15 \mathrm{ml}$ of ethylether. The ether layer was washed with $5 \mathrm{ml}$ of $0.01 \mathrm{~N}-\mathrm{HCl}$ and water. The ether layer was evaporated to dryness under $\mathrm{N}_{2}$ gas. The column $(0.5$ $\times 13.5 \mathrm{~cm}$ ) was prepared by suspending the silicic acid in benzene: ethyl acetate (60:40). The extracted PGs were dissolved in $0.5 \mathrm{ml}$ of benzene : ethyl acetate : methanol (60: $40: 10)$ and were applied to the column. $\mathrm{PGs}$ from the column were eluted with $15 \mathrm{~m}$ of benzene: ethyl acetate : methanol (60: 40: 10) (PGE fraction), after elution with $4 \mathrm{ml}$ of benzene : ethyl acetate (60:40) (14). The fraction of PGE was evaporated to dryness under $\mathrm{N}_{2}$ gas, and the activity of PGE was assayed using rat stomach fundus as previously described (7). This bioassay method enables a quantitation of as little as $50 \mathrm{pg}$ of $P G E_{2}$ and $150 \mathrm{pg}$ of $\mathrm{PGF}_{2 \alpha \text {. }}$

Urinary sodium and potassium were measured by flame photometry, and chloride by the method of Schales-Schales (15).

\section{RESULTS}

Figure 1 shows the relationship between the dose of xanthines and the response to the urinary PGE excretion and the urine volume. The urinary PGE excretion was significantly increased by p.o. administration of xanthines (25. 50 and $100 \mathrm{mg} / \mathrm{kg}$ ). In the case of theophylline, the urinary $P G E$ excretion reached the maximum with a dose of $50 \mathrm{mg} /$ $\mathrm{kg}$, and the increase was about 20 times in comparison with the level seen in the controls. On the other hand, theobromine and caffeine caused a dose-dependent increase of PGE excretion. The increase of the urinary PGE excretion by theobromine
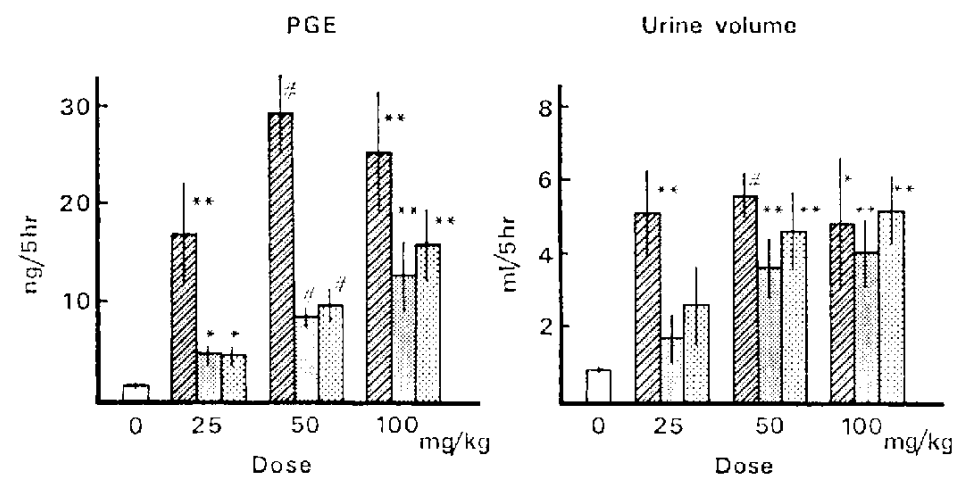

Fig. 1. Relation between dose and response of xanthines on urinary PGE excretion and urine

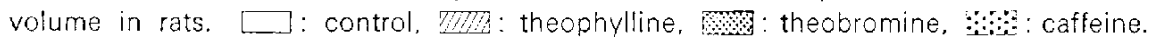
Drugs were suspended in $0.9 \% \mathrm{NaCl}$ solution and given in a volume of $0.5 \mathrm{ml} / \mathrm{rat}$ p.o. The control rats were given the same volume of $0.9 \% \mathrm{NaCl}$ solution. The control column represents the mean \pm S.E. of 19 rats, and each column represents the mean \pm S.E. of 10 rats. Significant difference from control ${ }^{*} p<0.05,{ }^{* *} p<0.01, * 00.001$. 
and caffeine was less than that seen with theophylline.

The urine volume was significantly increased by theophylline $(25,50$ and $100 \mathrm{mg} /$ $\mathrm{kg}$ ), and the maximum response was observed with a dose of $50 \mathrm{mg} / \mathrm{kg}$. The maximum increase was approx. 7.4 times over the control levels. Theobromine and caffeine significantly increased the urine volume, when given in doses of 50 and $100 \mathrm{mg} / \mathrm{kg}$.

The relationship between the dose of xanthines and their response to the urinary electrolyte excretion is shown in Fig. 2.

The urinary electrolyte excretion was significantly increased with the administration of theophylline. In particular, the urinary sodium excretion was enhanced about 9.6-13.5 times as compared with the control levels (potassium: 4.3-5.5 times, chloride: 5.5-7.6 times).

On the other hand, a significant increase of the electrolyte excretion was induced by theobromine and caffeine in doses of 50 and $100 \mathrm{mg} / \mathrm{kg}$. The increase in the urinary electrolyte excretion by theobromine and caffeine was minute compared with the response of theophylline.

Figure 3 shows the time course of urinary $P G E$, the urine volume and the sodium
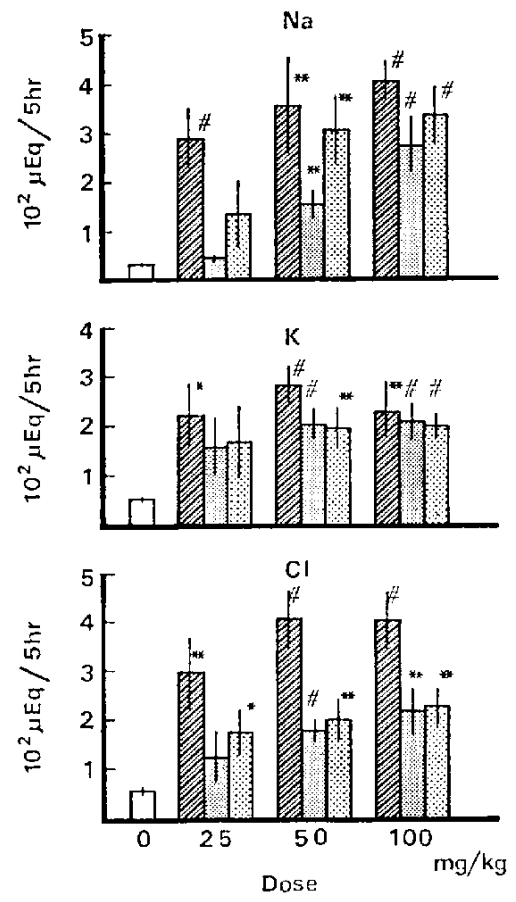

Fig. 2. Relation between dose and response of xanthines on urinary electrolytes excretion in rats. $\square$ : control. WTH: theophylline, $\$$ : theobromine, : caffeine. The experimental condition was the same as in Fig. 1. The control column represents the meantS.E. of 19 rats, and each column represents the mean \pm S.E. of 10 rats. Significant difference from control * $p<0.05,{ }^{*} p<0.01,{ }^{*} p<0.001$.

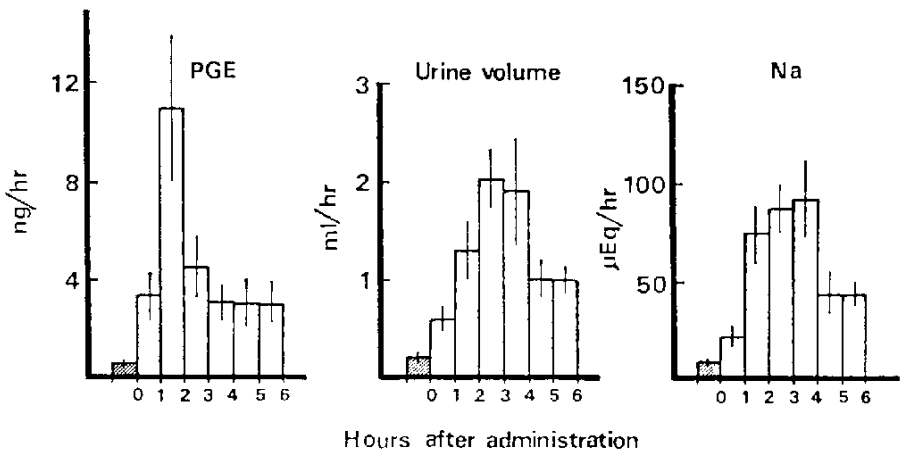

Fig. 3. Time course of urinary PGE excretion, urine volume and sodium excretion after theophylline administration. Theophylline $(50 \mathrm{mg} / \mathrm{kg})$ was given p.o. at time 0 . Height of the column of an oblique lines shows the result of a sixth part of the urine collected for $6 \mathrm{hr}$ before theophylline administration. Each column represents the mean $\pm S$.E. of 10 rats. 

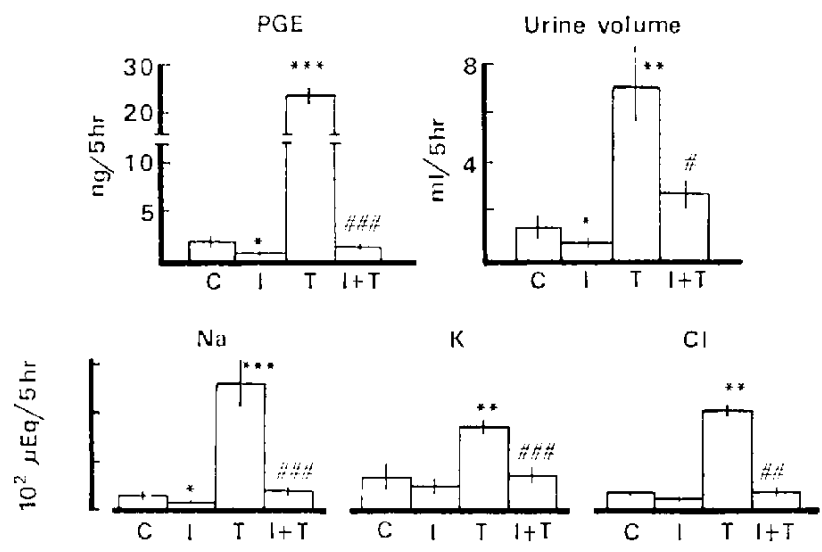

Fig. 4. Effect of indomethacin on urinary PGE excretion, urine volume and electrolytes excretion in rats. C: control I: indomethacin $10 \mathrm{mg} / \mathrm{kg}$ p.o. T: theophylline $50 \mathrm{mg} / \mathrm{kg}$ p.o. Theophyiline was administered $1 \mathrm{hr}$ after indomethacin administration. A pooled 5 hr urine sample was obtained after theophylline administration. Each column ropresents the mean+S.E. from 5 rats. Significant difference from control ${ }^{*} 0 \cdots 0.05$, " $p<0.01$."*p<0.001. Significant difference from T treated group " $p<0.05, * p<0.01$. 0.001 .

excretion at each hour after p.o. administration of theophylline in a dose of $50 \mathrm{mg} / \mathrm{kg}$.

The urinary PGE excretion remained markedly increased throughout the observed period after theophylline administration. The urinary $P G E$ excretion was maximum during the 1-2 hr period after theophylline administration. The peak of increase of the urinary PGE excretion preceded the peak of the urine volume and the urinary sodium excretion. The urine volume and the sodium excretion were maximum during the $2-4 \mathrm{hr}$ period after theophylline administration.

Figure 4 shows the effect of indomethacin on the urine volume, and the urinary PGE and electrolyte excretion.

The basal urine volume, the urinary PGE and sodium excretion were significantly reduced with p.o. administration of indomethacin $(10 \mathrm{mg} / \mathrm{kg}$ ) while no significant effects were seen on the levels of urinary potassium and chloride. Increase in urine volume, and the urinary PGE and electrolyte excretion induced by theophylline was inhibited considerably by pretreatment with indomethacin, and the values were similar to the levels seen in the control group.

\section{DISCUSSION}

We found that xanthines (especially, theophylline) markedly increase the urinary PGE and sodium excretion. It has been reported that the urinary $P G E$ excretion was increased by furosemide in humans (1). rabbits (5) and dogs (10), by ethacrynic acid in dogs (10) and by spironolactone in humans (12). This is the first report that xanthines increase excretion of urinary PGE.

Theophylline has potent diuretic action and caffeine has the least such action among the three derivatives used in our study. Theophylline proved to be the most potent and theobromine and caffeine were equal in the potency. This minor discrepancy may be due to differences in the assay method used to determine the diuretic effects, since many of the studies done by other workers were carried out by loading water or saline Theophylline was the most potent in increasing the urinary excretion of PGE, and theobromine and caffeine showed much the same effects (Fig. 1). 
It has been reported that the diuretic action induced by theophylline is due to a direct inhibition on tubular sodium reabsorption and its indirect action as a result of an enhancement of the renal blood flow (13).

On the other hand, $P G E_{2}$ inhibits sodium transport by its direct action on the epithelium of the collecting tubules in the rabbit $(16,17)$. It has been also reported, that $P G E_{2}$ inhibits net chloride transport across the medullary thick ascending limb of Henle in rats (18) and rabbits (19). These results suggest that endogenous $P G E_{2}$ in kidney may play an important role in the regulation of the urinary electrolyte excretion.

PGE produces vasodilation in the kidney of dogs (20) and rabbits (21). In rat kidney, however, $P G E_{2}$ increases the renat vascular resistance $(22,23)$ and enhances vasoconstriction (21). On the other hand, there have been reports on the physiological roles of the renal PGs in promoting the renal sodium and chloride excretion in rats (18, 24-26). The possibility that the inhibition in tubular sodium reabsorption affects the diuretic action by PGE more strongly than do changes in intrarenal hemodynamics was suggested. Therefore, from our present results it may be concluded that theophylline inhibits sodium reabsorption in the renal tubules following increases in PGE. There are also some reports that PGE inhibits the action of antidiuretic hormone (ADH) (27, 28). Accordingly, it is also considered that anti-ADH action of PGE may partly contribute to the diuretic action induced by theophylline.

Since the action of theophylline was confirmed to be the most potent at a dose of $50 \mathrm{mg} / \mathrm{kg}$. subsequent experiments were done using this dose of theophylline. In the experiment of the time course after theophylline administration (Fig. 3), the peak of urinary PGE excretion was observed prior to that of the sodium and urine volume. The maximum excretion of PGE occurred during the 1-2 hr period after theophylline administration. Recently. Hendeles et al. reported that serum theophylline concentration reached the maximum at $2 \mathrm{hr}$ after p.o. administration of theophylline to humans (29). Moreover, Olsen has reported that clonidine-induced water diuresis was preceded by an increased urinary PGE excretion in dog (30). On the other hand, Kirschenbaum and Serros have recently reported that the excretion of PGE may be dependent on the rate of the urine flow (31). Therefore, there are at least two possible explanations for the increase of urinary PGE excretion induced by theophylline administration. One possibility is that the increased urinary PGE excretion rate is associated with increases in the urine flow rate, as induced by theophylline. Another possibility is that theophylline may increase urinary PGE by stimulating the intrarenal PGE synthesis and/or release. However, our observation that the peak of urinary PGE excretion preceded the diuresis favours the latter possibility. Accordingly, these observations suggest, that renal PGE may play an important role in the diuretic action of theophylline.

Indomethacin, an inhibitor of cyclooxygenase was used to examine the role of PGs production in the mechanism of the diuretic action of theophylline (Fig. 4). The basal urinary PGE excretion, the urine volume and the sodium excretion were reduced by oral administration of indomethacin. Increase in urinary PGE excretion. the urine volume and the sodium excretion elicited by theophylline $(50 \mathrm{mg} / \mathrm{kg}$ ) were also inhibited by indomethacin, thereby revealing the close relation between renal PGs and the theophylline action.

Our results strongly suggest that renal PGE participates in appearance of diuretic action of theophylline in the rat kidney. 


\section{REFERENCES}

1) Abe, K., Yasujima, M., Chiba, S., Irokawa, N., Ito, T. and Yoshinaga, K.: Effect of furosemide on urinary excretion of prostaglandin $E$ in normal volunteers and patients with essential hypertension. Prostaglandins 14, 513-521 (1977)

2) Bowden, R.E., Ware, J.H., Demets, D.L. and Keiser, H.R.: Urinary excretion of immunoreactive prostaglandin $\mathrm{E}$ : A circadian hythm and the effect of posture. Prostaglandins 14, 151 161 (1977)

3) Frölich, J.C., Wilson, T.W., Sweetman, B.J., Smigel, M., Nies, A.S., Carr, K., Watson, J.T. and Oates, J.A.: Urinary prostaglandins identification and origin. J. clin. Invest. 55, 763-770 (1975)

4) Rosenblatt, S.G., Patak, R.V. and Lifschitz, M.D.: Organic acid secretory pathway and urinary excretion of prostaglandin $E$ in the dog. Am. J. Physiol. 235, F473-479 (1978)

5) Oliw, E. and Änggard, E.: Different effects of furosemide on urinary excretion of prostaglandin $E_{2}$ and $F_{2 x}$ in rabbits. Acta physiol. scand. 105, 367-373 (1979)

6) Oliw, E.: Acute unilateral ureteral occlusion increases plasma renin activity and contralatcral urinary prostaglandin excretion in rabbits. Europ. J. Pharmacol. 53, 95-102 (1978)

7) Takeuchi, K., Kogo, H. and Aizawa, Y.: Biclogical assay of prostaglandin in rat urine using fundus of rat stomach. Folia. pharmacol, japon. 76, 179-184 (1980) (Abs. in English)

8) Tannenbaum, J., Splawinski, J.A., Oates, J.A. and Nies, A.S.: Enhanced renal prostaglandin production in the dog. 1 Effect on renal function. Circulation Res. 36, 197-203 (1975)

9) Blasingham, M.C. and Nasjletti, A.: Contribution of renal prostaglandins to the natriuretic action of bradykinin in the dog. Am. J. Physiol. 237, F182-187 (1979)

10) Patak, R.V., Faden, S.Z., Rosenblatt, S.G., Lifschitz, M.D. and Stein, J.H.: Diureticinduced changes in renal blood flow and prostaglandin $E$ excretion in the dog. Am. J. Physiol. 236, F494-500 (1979)

11) Weber, P.C., Scherer, B. and Larsson, C.: Increase of free arachidonic acid by furosemide in man as the cause of prostaglandin and renin release. Europ. J. Pharmacol. 41, 329-332 (1977)

12) Chiba, S., Abe, K., Yasujima, M., Irokawa, N., Seino, M., Sakurai, Y., Sato, M., Otsuka, Y. and Yoshinaga, K: Effect of spironolactone on urinary excretion of immunoreactive pro- staglandin $E$ in essential hypertension and primary aldosteronism. Tohoku J. exp. Med. 124, 297-305 (1978)

13) Ludens, J.H., Willis, L.R. and Williamson, H.E.: The effect of aminophylline on renal hemodynamics and sodium excretion. Archs int. Pharmacodyn. Thér. 185, 274-286 (1970)

14) Arai, Y., Takeuchi, K. Yamada, K., Kogo, H. and Aizawa, $Y$ :: Influence of carrageenin inflammation on prostaglandin release from rat synovial membrane and action of anti-inflammatory drugs. Folia pharmacol. japon. 75, 765-769 (1979) (Abs. in English)

15) Schales, O. and Schales, S.S.: A simple and accurate method for the determination of chloride in biological fluids. J. biol. Chem. 140, 879-884 (1941)

16) Stokes, J.B. and Kokko, J.P.: Inhibition of sodium transport by prostaglandin $E_{2}$ across the isolated, perfused rabbit collecting tubule. J. clin. Invest. 59, 1099-1104 (1977)

17) Ino, Y. and Imai, M.: Effects of prostaglandins on $\mathrm{Na}$ transport in isolated collecting tubules. Pflügers Arch. 373, 125-132 (1978)

18) Higashihara, E., Stokes, J.B., Kokko, J.P., Campbell, W.B. and DuBose, T.D.: Cortical and papillary micropuncture examination of chloride transport in segments of the rat kidney during inhibition of prostaglandin production. J. clin. Invest. 64, 1277-1287 (1979)

19) Stokes, J.B.: Effect of prostaglandin $E_{2}$ on chloride transport across the rabbit thick ascending limb of Henle. J. clin. Invest. 64, 495-502 (1979)

20) Bolger, D.M., Eisner, G.M., Ramwell, P.W., Corey, E.J. and Slotkoff, L.M.: Renal actions of prostaglandin. Nature 271, 467-469 (1978)

21) Malik, K.U. and McGiff, J.C.: Modulation by prostaglandins of adrenergic transmission in the isolated perfused rabbit and rat kidnoy. Circ. Res. 36, 599-609 (1975)

22) Baer, P.G. and McGiff, J.C.: Comparison of effects of prostaglandins $E_{2}$ and $I_{2}$ on rat renal vascular resistance. Europ. J. Pharmacol. 54, 359-363 (1979)

23) Gerber, J.G. and Nies, A.S.: The hemodynamic effect of prostaglandins in the rat. Evidence for important species variation in renovascular responses. Circ. Res. 44, 406-410 (1979)

24) Düsing, R., Melder, B. and Kramer, H.J.: Prostaglandins and renal function in acute extracellular volume expansion. Prostaglandins 12, 3-10 (1976)

25) Düsing, R., Melder, B. and Kramer, H.J.: Effects of prostaglandin inhibition on intrarenal 
hemodynamics in acutely saline-loaded rats. Circ. Res. 41, 287-291 (1977)

26) Kadokawa, T., Hosoki, K., Takeyama, K., Minato, H. and Shimizu, M.: Effects of nonsteroidal anti-inflammatory drugs (NSAID) on renal excretion of sodium and water, and on body fluid volume in rats. J. Pharmacol, exp. Ther. 209, 219-224 (1978)

27) Albert, W.C, and Handler, J.S.: Effect of PGE indomethacin, and polyphloretin phosphate on toad bladder response to ADH. Am. J. Physiol. 226, 1382-1386 (1974)

28) Dunn, M.J., Greely, H.P., Valtin, G.H., Kinter, L.K. and Beeuwkes, R.B.: Renal excretion of prostaglandins $E_{2}$ and $F_{2 \alpha}$ in diabetes insipidus rats. Am. J. Physiol. 235, E624-627 (1978)

29) Hendeles, L., Weinberger, $M$. and Johnson, G.: Monitoring serum theophylline levels. Clin. Pharmacokinetics 3, 294-312 (1978)

30) Olsen, U.B.: Clonidine-induced increase of renal prostaglandin activity and water diuresis in conscious dogs. Europ. J. Pharmacol. 36 , 95-101 (1976)

31) Kirschenbaum, M.A. and Serros, E.R.: Effects of alterations in urine flow rate on prostaglandin E excretion in conscious dogs. Am. J. Physiol. 238, F107-111 (1980) 